\title{
CONTINUING THE CONVERSATION: THE CHOICE BETWEEN ADOPTION AND FOSTER CARE AS CHILD PROTECTION RESPONSES
}

\author{
LEAH BONFILI
}

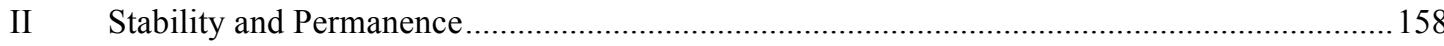

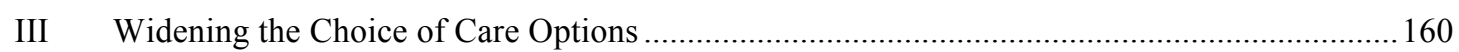

IV Listening to the Voices of Children in Out-of-Home Care .................................................... 161

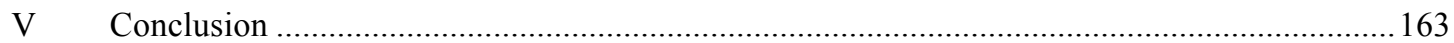

\section{INTRODUCTION}

The primary article by Stephen Gay raises some interesting points and the overall conclusion that no single model, no 'one-size-fits-all' solution is likely to provide a panacea for the ailments of the child protection out-ofhome care system is undeniably correct. Every child is different and meeting each child's needs should raise the possibility of more than simply making a choice between two responses, both of which arguably have a legitimate role to play in the child-protection system, and neither of which may be suitable for the long-term care of some children and young people. The more choices that are available for the care of children, the more likely we are to be able to find an option that meets their individual needs.

My research seeks to answer the question: are Tasmanian children living in long-term out of home care placements provided with care options that 'maximise [their] opportunity to grow up in a safe and stable environment and to reach [their] full potential ${ }^{1}$ — as was Parliament's intent when it passed the Children, Young Persons and Their Families Act 1997 (Tas) - or are other care options required to achieve this goal? The question posed in the primary article is one of many that I have asked in trying to arrive at an

LLB (Hons), PhD Candidate, Faculty of Law, University of Tasmania.

Children, Young Persons and Their Families Act 1997 (Tas) s 7. 
answer, and so this response will seek to expand the conversation started in the primary article by sharing some of the key themes that have arisen over and over again during the course of my research.

This response discusses the need for stability and permanence of care arrangements for children and young people living in out-of-home care in Part II before moving on in Part III to consider the option of widening the choice of care arrangements to better meet their needs. The importance of listening to the voices of children and young people and giving them a say in where they live and how they are cared for is also explored in Part IV.

Before proceeding, I need to make a declaration and also give a definition. First the declaration: when asked to write this response, I had to think carefully about engaging in this particular debate, which is one that I have avoided in the past for fear of perceived bias. I am the adoptive mother of two children who came into my life in very different ways: one as an adult adoption of a step-child, whom I had raised since he was a young boy; the other as an infant through inter-country adoption. I am not an advocate for adoption being the solution to the care needs of all children. However, my own experiences of parenting my two children tell me that it can be the best available option for some children and should certainly be one of the choices available to meet the needs of children where adoption would be in their best interests.

In my opinion, adoption should always be about finding a family for a child, not about finding a child for a family. Past adoption practices, such as forced adoptions, were more focused on finding a child for a family. In the modern child protection context, adoption is necessarily focused on finding a family for a child, and can only be justified on that basis.

Moving on to the definition: the term 'attachment' will come up many times during the course of this response. So what is it and why is it important? In a nutshell, attachment is the 'dependency relationship a child develops towards his or her primary caregivers'. ${ }^{2}$ Healthy, secure attachment relationships play a key role in the child's development, their perceptions of relatedness to others, their concepts of self and their life experiences. ${ }^{3}$ Perhaps Hughes best summed up why attachment is important when he said:

Colby Pierce, A Short Introduction to Attachment and Attachment Disorder (Jessica Kingsley Publishers, 2009) 13.

3 Ibid 16. 
All children, at the core of their beings, need to be attached to someone who considers them to be very special and who is committed to providing for their ongoing care. Children who lose their birth parents, especially those who have experienced the trauma of abuse and neglect, desperately need such a relationship if they are to heal and grow. ${ }^{4}$

The reason why stability and permanence are crucial for children and young people who require long-term out of home care is because they provide the ideal conditions for strong, healthy attachments to grow and develop between child and care giver. ${ }^{5}$

\section{Stability AND PERMANENCE}

As mentioned in the primary article, children and young people living in long-term foster care generally experience poorer outcomes in a number of key areas - education, employment, housing and youth parenthood compared to children who live in a stable family environment, such as those who live within their families of origin, in adoptive families or in permanent care arrangements. ${ }^{6}$ The key differences here are stability and the quality of the care relationships.

Quality care relationships develop when children have the opportunity to form strong attachments in stable placements. Strong attachments are essential for forming healthy, positive relationships in childhood and beyond; and have a clear influence on long-term life outcomes. ${ }^{7}$ This contrast in outcomes is by no means a reflection on the quality of the vast majority of foster carers, but instead reflects the reality that most children experience

Daniel A Hughes, Facilitating Developmental Attachment: The Road to Emotional Recovery and Behavioral Change in Foster and Adopted Children (Roman \& Littlefield Publishers, 1997) 1.

5 Child Safety Services, 'Permanency Planning' (Practice Paper, Department of Communities Queensland, May 2011) 4.

6 Judy Cashmore, Marina Paxman and Michelle Townsend, 'The Educational Outcomes of Young People 4-5 Years after Leaving Care: An Australian Perspective' (2007) 31 Adoption \& Fostering 50, 53; Judy Cashmore and Marina Paxman, 'Longitudinal Study of Wards Leaving Care: 4 to 5 Years On' (Report, Social Policy Research Unit, UNSW, January 2007) 41; Guy Johnston et al, 'Pathways from Out-of-Home-Care' (AHURI Final Report No. 147, Australian Housing and Urban Research Institute, April 2010) 25; Judy Cashmore and Marina Paxman, 'Wards Leaving Care: A Longitudinal Study' (Report, Social Policy Research Unit, UNSW, January 1996) 13.

Child Safety Services, above n 5. 
multiple, short-term placements in foster care, ${ }^{8}$ which inhibit their ability to form attachments.

This instability and/or lack of permanence is the problem that proponents of adoption as a child protection response seek to address by ensuring that the placement is intended to be permanent, stable and not easily challenged or disturbed. Foster care, on the other hand, by its very nature and design is intended to be a temporary measure. However, it is this temporary feature of foster care that has led to the 'drift in care' problems discussed in the primary article. Studies have generally found that adoption 'provides higher levels of emotional security, a stronger sense of belonging and a more enduring psychological base in life for those who cannot live with their birth families'. ${ }^{9}$ Despite the concerns raised in the primary article about adoption in both the child protection and traditional contexts, my research has not convinced me that adoption is not an appropriate response to meet some children and young people's long-term out-of-home care needs.

I would argue that for many policy and decision makers, the choice between adoption and foster care is not simply an emotional response, as was suggested in the primary article, but a choice based on currently available research and also grounded in the practicality of living with the two types of orders, for both children and their substitute parents. As Ormond LJ observed when speaking of the advantages of making an adoption order over an order for long-term fostering:

[A]doption gives us total security and makes the child part of our family, and places us in parental control of the child; long-term fostering leaves us exposed to changes of view of the local authority, it leaves us exposed to applications and so on, by the natural parent. This is a perfectly sensible approach, it is far from being an emotive one. ${ }^{10}$

Adoption, however, is not a suitable or desirable option for all children and young people in care, for a variety of reasons, but especially where the child or young person does not want to be adopted. This is why placement options for children and young persons requiring out of home care in Australia

8 Barnardos Australia, 'Explaining the Changes to New South Wales Child Protection Legislation' (Fact Sheet, Barnardos Australia) 1.

9 See for example, the meta-analysis of adoption and fostering studies from the United Kingdom: John Triseliotis, 'Long-term Foster Care or Adoption? The Evidence Examined' (2002) 7 Child and Family Social Work 23, 31.

$10 \quad \operatorname{Re}: H(1981) 3$ FLR 386, 388. 
currently include other arrangements such as permanent care (see below), family group homes, residential care and independent living arrangements. ${ }^{11}$

\section{WidENING THE CHOICE OF CARE OPTIONS}

As mentioned in the primary article, some international jurisdictions include other care options within their statutory frameworks, such as Special Guardianship in the UK and Simple Adoption in France. These orders do not fully sever parental rights and responsibilities, but instead create additional parenting rights and responsibilities for the long-term carers (generally foster parents) of the children subject to these orders.

Similar hybrid quasi-adoption models are currently found in all Australian child protection frameworks, where they are often referred to as permanent care orders. ${ }^{12}$ Like their international counterparts discussed in the primary article, their main flaws or weaknesses in terms of permanency appear to be: the relative ease with which the arrangements can be challenged; and the fact that the trigger for the challenge is the change in circumstances of the parent, not a change in the needs of the children living under the arrangements. ${ }^{13}$

The law in most jurisdictions has been very slow to recognise the importance to the child of the person who has become their 'psychological parent" ${ }^{\text {, }}$ (usually the foster parent), and often the "child becomes the "prize" of [their parent's] rehabilitation' ${ }^{15}$ because of these review mechanisms. For the children involved, this preference by the courts for biological connection

11 Australian Institute of Health and Welfare, 'Child Protection Australia 2013-14' (Child Welfare Series No. 61, AIHW, 2015), 46.

12 Children and Young People Act 2008 (ACT) ss 481-482; Children and Young Persons (Care and Protection) Act 1998 (NSW) s 79A; Care and Protection of Children Act (NT) s 137A; Child Protection Act 1999 (Q1d) ss 61-62; Children's Protection Act 1993 (SA) s 38(1)(d); Children, Young Persons and Their Families Act 1997 (Tas) s 41(4)(d); Children, Youth and Families Act 2005 (Vic) s 321; Children and Community Services Act 2004 (WA) s 60 .

13 Children and Young People Act 2008 (ACT) s 472; Children and Young Persons (Care and Protection) Act 1998 (NSW) s 90; Child Protection Act 1999 (Qld) s 65(1)-(3); Children's Protection Act 1993 (SA) s 40; Children, Young Persons and Their Families Act 1997 (Tas) s 48(1)(ab), Children, Youth and Families Act 2005 (Vic) s 326; Children and Community Services Act 2004 (WA) s 67.

14 Yvon Gauthier, Gilles Fortin and Gloria Je Liu, 'Clinical Application of Attachment Theory in Permanency Planning for Children in Foster Care: The Importance of Continuity of Care' (2004) 25(4) Infant Mental Health Journal 379, 393.

15 Ibid. 
over the attachment they have formed to their foster family is often difficult to comprehend, and can have significant on-going psychological effects including feelings of loss, grief and anger about their change in living arrangements if family reunification is ordered. ${ }^{16}$

Although I am not yet ready to make final recommendations from my research, a review of these trigger mechanisms to make them more centered on the needs of the child, rather than the circumstances of the parent will most likely be among the recommendations I ultimately make. If the needs/wishes of the child favour family reunification, this should still be an option. However, children must cease being 'prizes' in a battle between family reunification and permanency planning policies and should be given agency in their own lives and real input into the decision that affect them. We need to be listening to the voices of children and young people in care.

\section{LISTENING TO THE VOICES OF CHILDREN IN OUT-OF-HOME CARE}

As I began my literature review for my thesis, I noticed a scarcity of research in the field of child protection, which actually asked the children and young people in care what they wanted or needed from the system. Children are without doubt the most affected by the child protection system we have set up to 'care for' them, and yet we rarely hear their voices in research or policy development.

One of the few exceptions is the annual Report Card series published by the Create Foundation. This annual survey of children and young people in care in Australia is an opportunity for them to have a say about issues that affect them. Overwhelmingly, the respondents indicated a desire to have more meaningful input into the decisions that are made about their lives and care arrangements. ${ }^{17}$ As one young boy commented, we need to 'listen to kids more about where they want to live'. ${ }^{18}$

Another notable exception, where children and young people's voices have been heard by policy makers, can be found in the changes to the NSW legislation discussed in the primary article. These changes came about in part as a result of research conducted with children and young people in care in

16 Ibid 394.

17 Joseph J McDowell 'Experiencing Out-of-home Care in Australia: The Views of Children and Young People (CREATE Report Card 2013)' (Report, CREATE Foundation, 2013) 6771 .

$18 \quad$ Ibid 69. 
NSW who indicated that they wanted adoption to be prioritised as a longterm care option and that they wanted a time limit set for the making of permanency decisions. ${ }^{19}$ While the timeframes adopted by the NSW Government have been criticised as too short, ${ }^{20}$ they are considerably longer than the four to six weeks suggested by the children and young people themselves. $^{21}$

The feedback about permanency timeframes received from children and young persons in NSW with care experiences also accords with the clinical experiences of attachment therapists working with children in care. One group of practitioners commented:

We were constantly reminded that a "child's time" in the crucial early years is much shorter than the "adult's time:" A young child cannot wait for the parents to solve their persistent personality problems, childhood traumas, drug abuse, and violence. A child cannot be put "on hold."22

Because children cannot be 'put on hold', some Australian jurisdictions have placed time limits on children in care who are living under uncertain conditions, either through legislative ${ }^{23}$ or policy means. ${ }^{24}$ Aside from asking the children and young people in care in Tasmania how they would like their care arrangements structured, my research will also ask them about issues of timeliness in determining permanency or reunification, and what they think is a reasonable timeframe for these goals. The results should add to the growing body of research that seeks to give children and young people in care a say in decisions that affect their lives and living arrangements.

I am a passionate advocate for giving children and young people agency in their own lives. My own life experiences tell me that even very young children can have strong opinions about issues that affect them. In the same way that children who are affected by cancer understand more about the

19 Family and Community Services NSW, 'A Safe Home For Life: Report on the Outcomes of Public Consultations on the Child Protection Legislative Reforms Discussion Paper 2012' (Report, Family and Community Services NSW, 2013) 11, 25-26.

20 Anna Patty, 'Adoption Changes Could Create New 'Stolen' Generation say Community Groups', The Sydney Morning Herald, (Sydney), 11 November 2013, 47.

21 Family and Community Services NSW, above n 19, 29.

22 Yvon Gauthier, Gilles Fortin and Gloria Je Liu, 'Clinical Application of Attachment Theory in Permanency Planning for Children in Foster Care: The Importance of Continuity of Care' (2004) 25(4) Infant Mental Health Journal 379, 394.

23 Children and Young Persons (Care and Protection) Act 1998 (NSW) s 83; Children, Young Persons and Their Families Act 1997 (Tas) s 44(2); Children, Youth and Families Act 2005 (Vic) s 170.

24 Child Safety Services, above n 5. 
disease than their peers who do not have cancer experiences, ${ }^{25} \mathrm{I}$ believe that children who are in care understand more about various care options than most children who spend their entire childhoods in their families of origin. Both my children have complex and changing feelings about their life stories. And both have expressed strong opinions on adoption and related issues from young ages, because their lives have forced them to think about the issue more deeply than most. Whatever solutions are to be found to the out-ofhome care crisis we face in Australia, I believe that children and young people themselves, as the key stakeholders in the system, must be actively involved in the process of finding them. After all, it is their needs that the system seeks to meet, so who better to tell us what those needs are?

\section{CONCLUSION}

Stability and permanence have long been discussed in relation to foster care. I do not believe it is possible to overstate their importance to children and young people in general, and especially to those who may be particularly vulnerable due to their early life experiences. But stability and permanence alone are not enough; children need the loving, nurturing relationships that come only when strong, healthy attachments are formed with their care givers. By ensuring a stable and permanent family is found for a child or young person who cannot live within their family of origin, we offer them their best chance in life. No care option should be off the table if it is in the child's best interest. And most importantly, we should be giving children and young people a say in making these crucial decisions that have long lasting effects on their lives.

Perhaps conclusion is not an apt description for these final remarks, as I believe my response raises more questions than it offers answers. I would agree with the conclusion of the primary article that 'an automatic attempt to arrange adoption from care, as occurs in the US and to a lesser extent in the UK and NSW, is inappropriate as a default position.' There should be no default position as such, each child or young person's individual needs must be identified and the most appropriate care option for each should be chosen from among a wide variety of care options available to those making the enormous decision to alter the course of a child or young person's life forever. Adoption, foster care, and other care arrangements must all be

25 American Society of Clinical Oncology, How a Child Understands Cancer $<$ http://www.cancer.net/coping-with-cancer/talking-with-family-and-friends/how-childunderstands-cancer>. 
considered on their merits on a case-by-case basis. But in assessing each case on its individual merits the voices of the children concerned should be heard. 